\title{
The College Students' Innovative Entrepreneurial Education Based On Neural Networks Method in Internet Environment
}

\author{
Dong-Yun LUO ${ }^{a}$, Miao- Miao CAI ${ }^{\mathrm{b},{ }^{*}}$, Fang YOU ${ }^{\mathrm{c}}$ and Xiao-Qun ZHOU ${ }^{\mathrm{d}}$ \\ No. 551, Forward East Road Electronic Engineering College Jiujiang University, Jiujiang City, \\ Jiangxi Province \\ aldongyun2001@126.com, b23846494@qq.com, c314097876@qq.com, d504009266 @qq.com
}

\section{Keywords: College students; Entrepreneurial education; Neural networks}

\begin{abstract}
Based on the analysis of Internet $+"$ and the national strategic background of innovation and entrepreneurship, this paper expounds the connotation and essence of "Internet +", analyzes the necessity of constructing the information platform of college students' innovation and entrepreneurship under the environment of "Internet + ", using expert interviews and This paper analyzes the demand and platform function of college students' innovation and entrepreneurship under the environment of "Internet +", and use BP neural network to evaluate the college students' entrepreneurship education, which has certain theoretical and practical significance
\end{abstract}

\section{Introduction}

Under the background of Internet application, this paper discusses the "network + " model of entrepreneurship education in colleges and universities, using the "+" network of public information platform for entrepreneurship and innovation, especially in the current college students entrepreneurship encountered difficulties, how to solve the difficulties of new ideas and new mode has become college students' innovation and entrepreneurship education opportunities and challenges, "network +" under the background of college students' entrepreneurial quality appraisal, the domestic scholar has carried on the massive work, puts forward the fuzzy analysis and comprehensive evaluation method and evaluation method. However, the education evaluation index system of college students has a wide range, a single evaluation index, a complex quantitative method, and often a lack of comparability. There is a high nonlinear relationship between education and index. It is difficult to evaluate the whole index system with traditional methods. The neural network USES the physiological structure of human brain to study human's intelligent behavior and simulate the information processing function of human brain. It has characteristics of learning, fault tolerance, distributed storage and adaptive capacity. It is widely used in modeling, signal processing, prediction, identification and system control. Based on the adaptive and learning ability of neural network, BP neural network was established and the evaluation model of education was established. The model can complete the nonlinear mapping between input data (evaluation index) and output data (entrepreneur ship education quality) to make the evaluation result more effective.

Using neural network method to evaluate, through training and learning, the entrepreneurship education of empirical knowledge accumulation, and, without any fixed model is set up in advance and provide evaluation of the sample data, by the method can accurately describe the relationship between the parameters, and then obtain ideal results.

\section{Neural Network Algorithm}

We can simplify the number of nodes through fewer nodes and layers, not only scalable, but also more efficient training. Next, you need to determine the number of hidden layers and nodes. In general, the regression linear classifier only needs two layers, and the general classification problem, the three layers are sufficient. A three-tier neural network, the number of input and output nodes has been determined, the need to determine the middle layer (hidden layer) the number of nodes (1) the number of hidden layer nodes must be less than $\mathrm{N}-1$ ( $\mathrm{N}$ for the number of samples) 
(2) the number of training samples should be 5-10 times the connection right, in addition, it is best to group the sample, the model training many times, but also more than one-time training into a lot of training. The number of nodes as small as possible, simple network generalization ability is often stronger to determine the hidden layer node lower limit and upper limit, followed by traversal, to find a faster convergence, and the higher the number of nodes 。

Reverse feedback from the last layer that is the output layer, training the neural network for the classification of the last layer of the output can reflect the type of data records, the output layer as two neural units, data records belong to the first category of output. The output value of the first neuron of the layer is larger than that of the second neuron, and the other belongs to the second category. The weight and offset of the entire network are randomly selected, but the recorded category cannot be described by the output of the network. Therefore, it is necessary to adjust the weight value and the offset value of the network. By adjusting the parameters, the output value and the category the difference between the neural network optimization target for the output layer:

$$
E_{j}=O_{j}\left(1-O_{j}\right)\left(T_{\mathrm{j}}-O_{j}\right)
$$

The middle of the hidden layer through the next layer of all node error by weight accumulation and not directly with the data record category, the formula is as follows:

$$
E_{j}=O_{j}\left(1-O_{j}\right) \sum_{\mathrm{k}} E_{k} W_{j k}
$$

Where $W_{j k}$ denotes the weight value of the node $\mathrm{j}$ of the current layer, the weight value of the node $\mathrm{k}$ of the next layer, and the error rate of the node $\mathrm{k}$ of the next layer of $E_{k}$.

After calculating the error rate, you can use the error rate to update the weight and bias, where $\lambda$ represents the learning rate, the value is 0 to 1 , the learning rate is set too large, the training convergence faster, but easy to fall into the local optimal Solution rate is relatively small, the convergence rate is slow, but can be a step closer to the global optimal solution. First look at the weight update:

$$
\begin{aligned}
\Delta W_{i j} & =\lambda E_{j} O_{j} \\
W_{i j} & =W_{i j}+\Delta W_{i j}
\end{aligned}
$$

Figure 1 shows the learning error under the learning sample data.

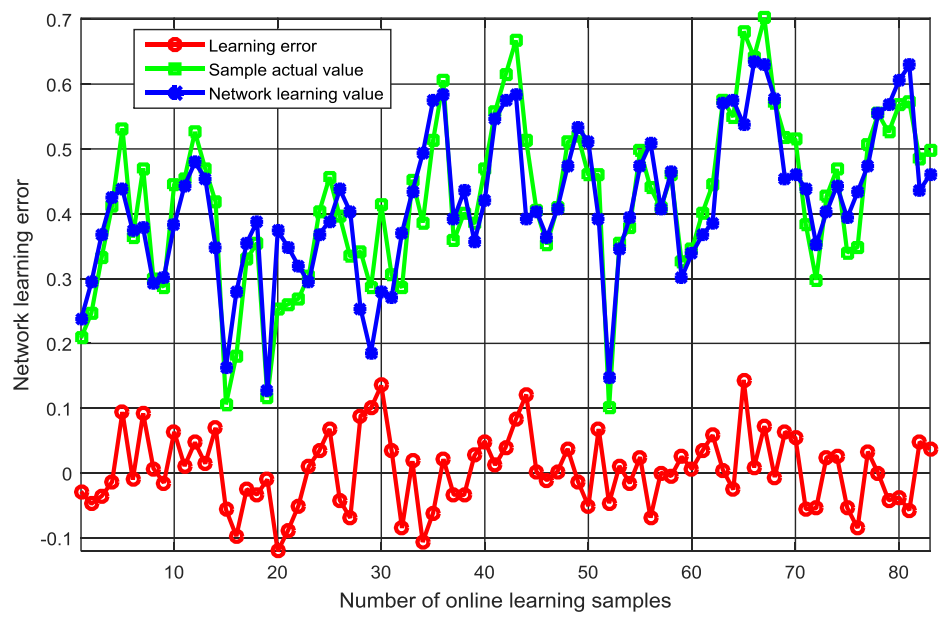

Figure1. Network learning error 


\section{College Students' Entrepreneurship Education}

As a kind of educational idea and mode of the new trend of modern education, especially higher education is the important content of innovation and entrepreneurship education has attracted widespread attention all over the world in 1985, the introduction of ideological innovation and entrepreneurship education in our country, many colleges and universities begin to establish pilot innovative entrepreneurship education, but due to the creative idea of long-term is bound by the examination oriented education, the to promote the work and achieved good results. Higher education management personnel will need to monitor and evaluate the quality of education in a more important position, an important link at this time is particularly important, the traditional education quality evaluation system of the evaluation standard is inflexible, standard system is not scientific, the evaluation method is relatively backward is not applicable to the evaluation of innovation and entrepreneurship education mode. Therefore, to establish a scientific evaluation index system through the model methods and training objectives of innovation and entrepreneurship, innovation and entrepreneurship education overall supervision of teaching and learning, teaching behavior and the standard and guide teachers to standardized assessment, assessment and detection of effective incentive and organization innovation, entrepreneurship education study and practice activities to effectively to promote the implementation and operation of innovative entrepreneurship education, has very important significance to enhance the overall performance of the research university, and became a very worthy of study. The logic and form of the commercial level are greatly influenced by the technical characteristics of the Internet and the mode of information dissemination. Micro-blog, WeChat and other new forms of entrepreneurial venture led to the Internet environment emerge in an endless stream "Crowd sourcing" to "create" and the emergence of new media, part of the entrepreneurial process management of product innovation and market demand orientation, marketing strategy and business model service mode with the characteristics of the Internet, according to the great differences in Colleges and universities in line with the principle of "education content education first and the traditional business model, focuses on the Internet and timely adjustment of entrepreneurship education content and increase knowledge in Internet entrepreneurship curriculum system, cultivate students' ability of creative thinking and the internet.

Cultivating students' innovative entrepreneurial thinking and ability can be summarized according to the technical form of the Internet, summed up the ability of college students to start the Internet thinking, the corresponding Internet innovation entrepreneurial knowledge system and teaching content can be designed on this basis. Market thinking ability, user thinking ability and product thinking ability and three categories can reflect the Internet thinking ability, college innovation and entrepreneurship education workers choose the appropriate teaching mode and methods to adapt to college students specific entrepreneurial way. You can also use the "concentration of the storm" to allow some successful Internet entrepreneurs to carry out the emergence of teaching and discuss how the Internet business. Again, the Internet thinking and innovation ability to develop subtle to include professional education, including all aspects of personnel training, so that students form a good Internet thinking ability. Finally, college students also in practice to achieve thinking skills migration application of Internet thinking and innovation. Through the real entrepreneurial activities and writing business plan, to participate in entrepreneurial competition to strengthen the students' Internet thinking and innovation ability to improve the success rate of entrepreneurship.

\section{Conclusion}

The artificial neural network method is a nonlinear mapping method. Unlike other evaluation methods such as fuzzy comprehensive evaluation method, gray clustering method and analytic hierarchy process, it is necessary to input the processed data into the network. The results can be calculated by calculation, do not need to manually determine the weight, does reduce the evaluation process of human factors, improve the evaluation of the reliability of the evaluation results more effective and more objective. It is one of the important means to promote the transformation and upgrading of college students' entrepreneurship education by integrating the artificial neural network method into 
the construction of "Internet + Creative Entrepreneurship Education" in colleges and universities. Through the concept of education, Professional, entrepreneurial "five links in the curriculum system to achieve the" post, card, class, race, a "five-level integration, and strengthen the innovation and entrepreneurship education team construction and platform construction, integration and sharing of resources, will be able to get out of business A new model of the virtuous circle of education.

\section{Acknowledgments}

This work was supported by the research subject on the teaching reform of provincial teaching in Jiangxi Province (Grant Nos. JXJG-15-17-416).

\section{References}

[1] Wang Hui, Li Yinhai. High-tech enterprise technology creation based on BP neural network New capacity evaluation, [J]. Science and technology management research, 2007, (11)

[2] Chen Jianxin,BP neural networks. Application of risk assessment in enterprise technology innovation [J]. Science and technology management research, 2007, (10)

[3]Feng Hua, Wang Zhenhong. Analysis of College Students' Entrepreneurship under the financial crisis [J]. Business age, 2009, (7)

[4]Peng Lu, et al. Preliminary study on the index system of College Students' entrepreneurial quality [J]. Science and technology entrepreneurship, 2008, (2)

[5] Zhou Yingjun. Research on the problems and countermeasures of entrepreneurial education in colleges and universities in China [J]. Zhengzhou University, Journal of Philosophy and Social Sciences, 2010 (1):174-176.

[6] Tu Dehu. On the curriculum system of college students' entrepreneurship education [J]. Heilongjiang Higher Education Research, 2009(10):178-180

[7] Sang Dawei, Xie Fuji. An Analysis of the Current Situation of Entrepreneurship Education in Chinese Universities and Its Counter measures [J].Now On behalf of management science, 2010 (4): 48-50.

[8] Wang Baoyi. Research and Enlightenment of Entrepreneurship Education in Western Countries

[J]. Theory and Practice of Education Practice, 2011 (15) 